Esta obra se propôs a fazer uma análise do passado, o presente e o futuro do sistema de governo brasileiro, sob o enfoque das origens, as características e a conjuntura que perpassam o mais atual arranjo institucional pátrio, denominado de presidencialismo de coalizão.

Como se sabe, o sistema de governo presidencialista foi uma criação teórica dos fundadores do Estado norte-americano, e desenvolveu-se no contexto das Revoluções liberais-clássicas do século XVIII. Desde então, com significativa estabilidade democrática, alternância de poder e efetivos mecanismos de freios e contrapesos, os Estados Unidos consolidaram esse sistema de governo, que serviu de modelo referencial para diversos países, incluindo o Brasil.

Por aqui, o presidencialismo foi importado e implementado no arranjo institucional a partir da Proclamação da República em 1889, inserido no contexto de renascimento liberal, de influência dos ideais da Revolução americana, de combate às desigualdades regionais do país e de oposição à monarquia e ao Poder Moderador.

Entre 1891 e 1930, verificou-se que a Constituição de 1891 por si só, não foi capaz de assegurar a proteção das instituiçóes contra o excesso de poder pessoal dos governantes, gerando, portanto, um desequilíbrio de forças entre Executivo e Legislativo, em favor do primeiro.

Na primeira experiência presidencialista brasileira, apesar dos inúmeros mecanismos para controle e fiscalização do governo por parte do Poder Legislativo e a separação de Poderes, a prática política de 1890 a 1930 desenvolveu-se com enorme pactuação entre os membros do governo e os membros do Parlamento, por meio, por exemplo, da composição de uma sólida aliança com os Governadores dos Estados, inserido no contexto da "política dos governadores". Segundo Sérgio Abranches, já residia ali, no arranjo institucional da República Velha, o embrião da sustentação do presidencialismo brasileiro, até os dias atuais, por coalizões majoritárias no Congresso, como forma de garantir as condições de governabilidade.

Com a Revolução de 1930 e o processo Constituinte de 1933-34, rompe-se com a primeira experiência presidencialista e inaugura-se uma nova etapa, destacando-se o embate de dois grandes grupos políticos: os restauradores liberais e os reformadores. Daquele processo político destaca-se, entre as principais inovações, a adoção do sistema de voto proporcional e a fixação de limites mínimos e máximos no número de deputados por Estados - cujas consequências institucionais podem ser verificadas até os dias atuais. 
Com o golpe do Estado Novo e a Constituição de 1937 encerra-se a segunda fase e inicia-se a terceira experiência presidencialista no Brasil, com forte concentração de poderes presidenciais e o fortalecimento do Poder Executivo, em detrimento dos demais Poderes.

O processo de manutenção do sistema presidencialista com acentuada concentração de poderes no Executivo, com viés ideológico bastante autoritário e centralizador, teve o apoio das Forças Armadas, dos setores econômicos e das forças políticas tradicionais. Entre as principais inovações destaca-se a introdução, no Brasil, do instituto do decreto-lei.

A quarta fase presidencialista no Brasil inicia-se com o fim do Estado Novo, a renúncia de Getúlio Vargas e a redemocratização. Nesse período, em que pese o inédito pluripartidarismo, com significativa fragmentação da representação partidária no Congresso. Nesse contexto de redemocratização, a Constituição de 1946 buscou desinflar o Executivo e fortalecer o Legislativo e Judiciário, garantindo-lhes maior autonomia e mecanismos de controle sobre as ações do governo, e de limitação do Poder Executivo.

No período democrático de 1946 a 1964, o presidencialismo, o sistema de voto proporcional e o pluripartidarismo deram ao país a primeira versão do presidencialismo de coalizão, no qual os Presidentes do período precisaram construir coalizões governamentais multipartidárias para obtenção do apoio majoritário no Congresso.

Entretanto, na versão de 1946 a 1964, esse presidencialismo de coalizão caracteriza-se pela grande instabilidade política do período em razão da paralisia decisória derivada dos duros embates e dos impasses gerados entre o Executivo e o Legislativo. Nesse sentido, haveria uma relação direta entre a instabilidade política dos Presidentes do período e a dificuldade, quase instransponível, de que eles conseguissem compor amplas bases de apoio dentro do Parlamento.

Entre as possíveis causas desse impasse entre o Poder Executivo e o Poder Legislativo no presidencialismo de 1946 a 1964, destaca-se o fato de que a Constituição de 1946 manteve regras eleitorais, como o sistema proporcional, reforçou o pluripartidarismo no país, cujas diversas correntes passaram a ter maciça representatividade no Congresso Nacional, ao passo que diminuiu significativamente os instrumentos de condução política do Presidente da República, que passou a depender mais do Poder Legislativo para implementar seu programa de governo. Além das deficiências institucionais do período, a polarização política, o radicalismo e a atuação dos militares foram fatores determinantes para a consolidação do golpe de 1964 que interrompeu a quarta experiência presidencialista brasileira.

No período de regime militar - de 1964 a 1985, o Brasil vivenciou sua quinta experiência presidencialista, caracterizada, assim como no período autoritário de 1937 a 1945, pela sobreposição do Poder Executivo aos Poderes Legislativo e Judiciário, com acentuada concentração de poderes, atribuições e prerrogativas no Presidente da República, em especial para a condução do processo legislativo pátrio, com o retorno, por exemplo, do instituto do decreto-lei. 
Com o fim da ditadura e a Constituição de 1988, o Brasil inaugura um novo período democrático, por meio da realização de eleições livres e periódicas para a escolha de seus representantes no Poder Executivo e Legislativo. Entretanto, da análise dos trabalhos da Assembleia Nacional Constituinte de 1987-1988, verificou-se que, ao menos originalmente, os Constituintes não pretendiam retomar a adoção do sistema de governo presidencialista.

Isso porque, na etapa de discussão do texto constitucional nas Comissões, forjou-se um sistema de governo parlamentarista. Entretanto, ao longo dos trabalhos constituintes, houve uma abrupta inflexão já na fase de deliberação em Plenário, com a aprovação de uma emenda, substituindo totalmente a redação do Capítulo do Poder Executivo, para a inserção do sistema de governo presidencialista.

A mudança do sistema de governo da forma como se deu na Constituinte, sem repactuação da correlação entre os Poderes Legislativo e Executivo, sem redistribuição de competências federativas, sem reorganização dos sistemas partidário e eleitoral, que haviam sido pensados sob a égide de um sistema parlamentarista, forjaram, portanto, esse presidencialismo que caracteriza a Nova República pós-1988.

Com tais pressupostos, verifica-se que a Constituição de 1988 foi tímida no objetivo de descentralizar o sistema de repartição de competências e recursos, mantendo, em grande parte, o desequilíbrio do pacto federativo em favor da Uniáo, ao mesmo tempo em que ampliou os poderes do Presidente da República, desequilibrando a tripartição dos Poderes em favor do Executivo.

Essa exacerbação do presidencialismo na Constituição de 1988, a partir da hipertrofia do Poder Executivo, centralizado na figura do Presidente da República, de que tratam diversos autores, pode ser dimensionada a partir da análise da produção legislativa entre 1988 e 2018, que demonstram que em todos os períodos presidenciais do período, sem exceção, o Poder Executivo ocupou e ocupa papel preponderante na condução da agenda legislativa.

Nesse sentido, diferentemente da experiência presidencialista entre 1946-64, a partir de 1988 é o Poder Executivo, por meio de proposição de leis e medidas provisórias quem tem pautado a atuação do Congresso Nacional, provocando o Parlamento a se manifestar quanto à agenda de Estado e de governo proposta pelos Presidentes da República.

Se é certo que a Constituição de 1988 visava conferir maior poder de controle do Executivo sobre a condução das proposições de seu interesse no Parlamento, também é verdade que o modelo adotado - na maior parte dos períodos presidenciais - exacerbou nos poderes conferidos ao Presidente, na medida em que recorrentemente colocou o Parlamento em posição institucional inferior, ferido em sua autonomia política e prejudicado para o desempenho de suas prerrogativas, em especial aquelas que se referem à elaboração, modificação e aprovação das proposições legislativas.

Paralelamente ao aumento de poderes do presidente para conduzir sua agenda, a Constituição assegurou ao Congresso Nacional diversos instrumentos de fiscalização e 


\section{•- O presidencialismo de coalizão no Brasil}

controle sobre o Poder Executivo. Entretanto, da análise do funcionamento desses mecanismos de fiscalização e controle do Parlamento, é possível concluir que com frequência o Legislativo absteve-se de exercer seu papel institucional, exercendo-o apenas nos momentos de conturbada conjuntura, provocadas no contexto de crises político-partidárias entre o Presidente da República e suas respectivas bases de sustentação parlamentar.

Traçados todos os aspectos práticos e a conjuntura política e institucional dos últimos 30 anos, é possível concluir que o aumento dos poderes presidenciais resultou, por consequência, ainda que paradoxal, no aumento de sua dependência em relação ao Poder Legislativo.

Isso porque, ao longo do período ora analisado, os Presidentes da República precisaram recorrer à formação de amplas bases de apoio político-parlamentar como forma, não apenas de evitar os processos de impeachment, a convocação de Ministros, a rejeição de suas contas anuais e a realização de CPIs, mas também para poder exercer a plenitude de suas funções - por meio da edição de MPs, proposição de leis e condução da agenda legislativa e governamental.

E é justamente nessa dinâmica da relação entre Executivo e Legislativo pós 1988 que se insere a definição do arranjo institucional brasileiro contemporâneo denominado de "presidencialismo de coalizão".

Como se buscou demonstrar, a lógica do presidencialismo de coalizão sequer é nova no arranjo institucional brasileiro, tendo se manifestado com características bastante similares, durante o período entre 1946 e 1964. Em síntese, esse sistema de governo seria resultante da combinação de cinco elementos, que historicamente forjaram e ainda compõem o arranjo institucional brasileiro: o presidencialismo, o federalismo, o bicameralismo, o multipartidarismo e a representação proporcional.

Nesse sentido, por haver essa combinação singular entre o sistema multipartidário, o voto proporcional e o presidencialismo, verificou-se, na prática, a necessidade quase iminente de composição do Poder Executivo com base em grandes coalizões de sustentação político-parlamentar.

Para diversos autores, o presidencialismo de coalizão seria uma espécie de sistema de governo híbrido com a fusão de características presidencialistas e parlamentaristas, e a gênese desse modelo híbrido estaria na conjuntura da própria Assembleia Nacional Constituinte que referendou este modelo.

O que se tem no Brasil, portanto, é um arranjo institucional bastante paradoxal, que conjuga um Presidente da República forte e altamente demandado, com um Parlamento provido de múltiplos instrumentos de controle, mas fragmentado e bastante heterogêneo - reside aqui o fundamento lógico do presidencialismo de coalizão.

Isso porque ao mesmo tempo em que é poderoso e altamente relevante no quadro político e institucional brasileiro, o presidente é absolutamente dependente do Parlamento, que por sua vez, embora não possa tomar as decisóes em nome do governo, possui amplos mecanismos de freios e contrapesos que possibilitariam, caso exercidos 
com plenitude, frear as decisões governamentais e controlar a velocidade com que a pauta presidencial é implementada - podendo, inclusive, bloqueá-la.

Para que consiga governar e efetivamente impor seu poder de agenda, o Presidente da República precisaria, necessariamente, de apoio da maioria dentro do Congresso Nacional.

Como nenhum Presidente conseguiu eleger-se e obter, apenas com seu partido ou coligação eleitoral, a maioria no Parlamento, não resta alternativa ao Presidente, no presidencialismo de coalizão, que não seja a formação de coalizões multipartidárias que possibilitem a obtenção da maioria parlamentar como forma de assegurar a governabilidade, ou seja, a capacidade de impor a sua agenda legislativa e de se blindar contra os mecanismos de controle de que dispóe o Congresso.

Nesse sentido, entre 1988 e 2018, os Presidentes da República puderam dispor de dois instrumentos principais para azeitar as relaçôes com o Legislativo, atrair os partidos políticos e formar suas bases de apoio político-parlamentar, quais sejam: as nomeações em Ministérios e órgãos públicos e a liberação de emendas parlamentares.

Entretanto, tais custos da manutenção das coalizōes geram ineficiências colaterais para o desempenho dos Poderes Executivo e Legislativo, comprometem a própria noção de administração pública, viciam o processo decisório, tornando, portanto, essa sistemática do presidencialismo de coalizão bastante problemática do ponto de vista político e institucional.

Além disso, verifica-se a baixa previsibilidade quanto à coesão e durabilidade das coalizôes, a falta de incentivos à afinidade programática e aos riscos para a produção legislativa e para a qualidade das políticas públicas, como impactos colaterais desses custos do presidencialismo de coalizão.

Nesse sentido, a política, a negociação programática, a convergência ideológica e o interesse público, que devem nortear a atuação governamental e parlamentar, vão dando lugar ao fisiologismo, à negociação pragmática, à convergência meramente circunstancial e ao interesse eleitoral, partidário ou até mesmo estritamente pessoal na tomada de decisões por partes dos agentes públicos.

E a situação tem se agravado a cada novo período presidencial, a partir da deterioração do fenômeno da proliferação de partidos políticos no Brasil. Tal fenômeno impulsionado com o afrouxamento da fidelidade partidária e a outras intervenções indevidas no sistema partidário terminam por incentivar a falta de coesão e disciplina partidária, o fisiologismo em substituição à ideologia programática, e a proliferação de pequenos e médios partidos no Brasil.

Conforme o cenário de fragmentação partidária se agrava, diluindo a concentração de parlamentares nas bancadas tradicionais e ampliando a força e a representatividade de partidos pequenos e médios - muitos dos quais sem qualquer definição programática ou ideológica - aumentaram-se, consequentemente, as dificuldades na interlocução entre governo e Congresso, e por óbvio, os custos para formação e manu- 
tenção das coalizões. Não por acaso, como consequência desse processo de deterioração política verificou-se o processo de conversão do presidencialismo de coalizão em presidencialismo de cooptação.

As disfuncionalidades do arranjo institucional do presidencialismo de coalizão manifestaram-se, também, no âmbito do Poder Judiciário, a partir do excessivo aumento na judicialização dos conflitos de natureza política, diante da ineficiência dos Poderes Executivo e Legislativo em desempenharem suas funçōes e efetivamente solucionarem os conflitos de natureza política.

Nesse sentido, a excessiva judicialização da política desdobra-se em duas vertentes bastante problemáticas - efetivas disfuncionalidades do poder Judiciário no presidencialismo de coalizão, quais sejam: o ativismo judicial e a politização do Judiciário.

O ativismo judicial, como demonstrado, apesar de um fenômeno que não é exclusivamente brasileiro e motivado por uma série de outros fatores, guarda relação de causa e consequência com esse arranjo institucional pós-1988, a partir do qual o Judiciário do STF às instâncias inferiores - toma para si as competências e atribuições que seriam inerentes aos demais Poderes. Além disso, a atuação excessivamente ativa do Judiciário e a exacerbação de suas competências tendem a transformar os magistrados em atores políticos, colocando em risco sua imparcialidade e independência, tornando o Poder Judiciário mais vulnerável às críticas e às pressões da opinião pública, e com alto potencial para comprometer o desempenho institucional do próprio Poder Judiciário.

$\mathrm{Na}$ análise das conclusões ainda merecem destaque os riscos inerentes ao presidencialismo de coalizão, largamente vivenciados nas últimas três décadas.

Embora o presidencialismo de coalizão da Constituição de 1988 seja mais resistente aos abalos políticos e econômicos do que o presidencialismo de coalizão experimentado entre 1946 e 1964, não se pode descartar que o atual arranjo político não foi capaz de enfrentar os riscos desse sistema de governo.

Referimo-nos aos três tipos de riscos - de diferentes gradações - potenciais quando há crises entre o Presidente e suas coalizões: a paralisia decisória, as pautas bomba e as crises disruptivas.

Entendendo as pautas bomba e as crises de paralisia decisória como de menor potencial, não se pode dizer o mesmo das crises disruptivas. Nesse sentido, não há como negar o impacto institucional e as disfuncionalidades graves desse sistema de governo, verificados, por exemplo, nas sucessivas crises disruptivas que interromperam o mandato de dois dos quatros Presidentes eleitos no período entre 1988 e 2018, por meio de processos de impeachment.

Para além da análise concreta dos processos de impeachment e as singularidades de cada uma das crises políticas vivenciadas pela Nova República, é preciso aqui recolocar o entendimento de que as crises disruptivas que levaram a interrupção de mandatos presidenciais após 1988 são efeitos colaterais que também indicam as disfuncionalidades e as deficiências institucionais do sistema de governo brasileiro forjado a partir da Constituição de 1988. 
É preciso reconhecer, portanto, que essa a dependência de coalizões majoritárias no presidencialismo de coalizão, como condição para a própria sobrevivência do governo e continuidade do mandato presidencial é uma das - senão a mais grave - disfuncionalidades do arranjo institucional brasileiro, além de que contamina e compromete o próprio desempenho dos Poderes Executivo e Legislativo.

Por todo o exposto, entendemos que a fragmentação partidária exacerbada, o baixo desempenho do Legislativo, a hipertrofia do Executivo, o ativismo judicial desmensurado e a politização do Judiciário, o presidencialismo de cooptação e as sucessivas crises disruptivas por meio do instituto do impeachment como recurso para solução dos impasses do sistema e substituição de presidentes minoritários, são algumas das disfuncionalidades do arranjo institucional brasileiro que comprometem o desempenho dos Poderes e contaminam a vitalidade do presidencialismo brasileiro.

Ainda enfrentamos o desafio de pensar o futuro do sistema de governo brasileiro.

Nesse sentido, a partir da concepção de que o sistema presidencialista - que perdura há mais de 130 anos, poderia ser mantido, listamos uma série de proposições medidas legislativas e institucionais com a intenção de restaurar nosso arranjo político, assegurando o funcionamento e a credibilidade das nossas instituiçôes, a qualidade da democracia brasileira e a preservação do interesse público nacional, dentro de um contexto amplo de reforma política.

Entre as diversas propostas sugeridas, destacamos as mudanças no sistema eleitoral e partidário, tais como: a) adoção do voto distrital ou distrital misto para eleiçôes legislativas; b) maior redução e controle dos custos de campanha; c) efetivo controle pela justiça eleitoral dos mandatos dos dirigentes partidários; d) maiores garantias de acesso às condiçōes igualitárias para aqueles que desejem disputar cargos eletivos; e) estabelecimento de desincentivos para a criação de novos partidos; f) aumento da rigidez nas regras de fidelidade partidária para detentores de mandatos no Executivo e no Legislativo; g) retomar a verticalização das coligações; e h) revogar a previsão de janelas partidárias periódicas.

Além disso, propusemos mudanças relativas aos Poderes Executivo, Legislativo e Judiciário: a) redistribuição de competências entre os entes federativos para descentralizar as atribuições da União; b) desconcentração de competências do Presidente da República; c) aprimorar os mecanismos de controle prévio e a posteriori, do Congresso Nacional, para controlar e fiscalizar as ações governamentais; d) disciplinar a questão das medidas provisórias, ampliando a possibilidade do Congresso Nacional intervir no seu processo de tramitação; e) regulamentação dos grupos de pressão e do lobby no Brasil; f) corrigir as distorções na representatividade proporcional das populações dos Estados na Câmara dos Deputados; g) revogação da emenda da reeleição; h) aumento do mandato presidencial de quatro para cinco anos; i) aposentadoria compulsória a ex-presidentes; j) implementação do recall no Brasil; k) a adoção de novos procedimentos para a nomeação dos cargos, conferindo, por exemplo, ao Congresso 


\section{-• O presidencialismo de coalizão no Brasil}

Nacional a prerrogativa para sabatinar todos os Ministros de Estados e emitir parecer antes de sua nomeação pelo Presidente da República; 1) adoção de processos de seletivos públicos, com a possibilidade de indicação de nomes e instalação de "comitês de busca”, como forma de avaliar currículos e preparar listas tríplices para a escolha do Presidente da República; m) transformar o STF em efetivo Tribunal Constitucional, com diminuição de suas competências, mandatos fixos e aprimoramento do processo de investidura dos Ministros.

Discutiu-se ainda, eventual substituição do sistema de governo presidencialista no Brasil, com propostas para adoção do parlamentarismo ou de regimes mistos, como o semipresidencialismo.

Nesse sentido, para diminuir quaisquer riscos jurídicos e ampliar a legitimidade democrática de eventual mudança, defendemos que qualquer discussão a respeito da substituição do sistema de governo seja encaminhada e votada no âmbito do Congresso Nacional, por meio do processo legislativo próprio para as emendas à Constituição, e posteriormente seja submetida à consulta da população por meio de referendo.

Em relação ao parlamentarismo, destacamos que se trata de sistema de governo que consolida um arranjo institucional de efetiva interdependência entre o governo e o Parlamento, na qual só há formação e continuidade do governo com respaldo político e apoio parlamentar dos partidos. Entretanto, a substituição do sistema de governo com perda do protagonismo político da tradicional função do Presidente da República sem um regime de transição e sem mudanças socioculturais que possibilitem tamanha ruptura, poderia gerar distorções funcionais e dificultar a adaptação e consolidação do parlamentarismo no Brasil.

Por sua vez, os regimes mistos ou intermediários, como aqueles adotados na França e em Portugal, poderiam ser capazes de oferecer uma alternativa para a superação do presidencialismo de coalizão brasileiro sem maiores riscos políticos e institucionais, e sem tantos obstáculos sociológicos e culturais.

Além de tais ponderações, como demonstrado anteriormente, a substituição do sistema de governo sem modificações estruturais no sistema eleitoral e partidário seria inócua e faria com que enxertássemos em um eventual sistema parlamentarista ou semipresidencialista os mesmos vícios e os mesmos problemas estruturais que diagnosticamos no presidencialismo de coalizão que caracteriza o atual arranjo institucional brasileiro.

Não pretendemos aqui encerrar as discussões e dar uma resposta definitiva para essa questão. Trata-se de um rico e necessário debate quanto aos desafios, a conjuntura e o futuro do sistema de governo brasileiro, ao qual este trabalho pretende ser um colaborador adicional. Ainda que não se pretenda substituir o sistema de governo ou implementar uma profunda revisão constitucional a respeito do nosso sistema político, entendemos como fundamental que esse debate seja levado adiante pelos pesquisadores nas Universidades, pela opiniāo pública e pelo Parlamento, para que possamos efetivamente, enfrentar as deficiências do nosso modelo atual e implementar as mudanças pelas quais o país necessita passar. 